\title{
ADITIVOS ANTIBIÓTICO, PROBIÓTICO E PREBIÓTICO EM RAÇÕES PARA LEITÕES DESMAMADOS PRECOCEMENTE
}

\section{ADDITIVE ANTIBIOTIC, PROBIOTICAND PREBIOTIC FOR EARLYWEANED PIGLETS}

\author{
Asdrubal Viana Santos ${ }^{1}$ \\ Elias Tadeu Fialho² \\ Márcio Gilberto Zangerônimo ${ }^{*}$ \\ Vinícius de Souza Cantarelli² \\ Tiago da Silva Teofilo² \\ Juliano Pelição Molino³ \\ ${ }^{1}$ Instituto Federal do Espírito Santo- Campus Itapina, Colatina, ES, Brasil \\ ${ }^{2}$ Universidade Federal de Lavras, Lavras, MG, Brasil \\ ${ }^{3}$ Escola Superior São Francisco de Assis - Santa Tereza, ES, Brasil \\ *Autor para correspondência - zangeronimo@dmv.ufla.br
}

\section{Resumo}

Objetivou-se avaliar a adição do prebiótico mananoligossacarídeo (MOS 0,2\%), probiótico (Bacillus subtilis $30 \mathrm{~g} /$ tonelada) e antibiótico (bacitracina de zinco $125 \mathrm{~g} /$ tonelada) em rações para leitões na fase de creche. Utilizaram-se 80 leitões (Danbread x Agroceres), sendo 40 machos e 40 fêmeas, com peso inicial de $7,1 \pm 0,0175 \mathrm{~kg}$, distribuídos em delineamento de blocos ao acaso, com quatro tratamentos e cinco repetições: 1 - controle; 2 - prebiótico; 3 - probióticos; e 4 - antibiótico. As variáveis avaliadas foram ganho de peso diário (GPD), consumo de ração diário (CRD), conversão alimentar (CA), consistência fecal e leucometria global. Aos 43 dias de idade, os animais apresentaram o mesmo ganho de peso $(\mathrm{P}>0,05)$, porém, a dieta contendo prebiótico aumentou o consumo $(\mathrm{P}>0,05)$; a conversão alimentar foi melhor na dieta controle $(\mathrm{P}<0,05)$. No período de 54 dias de idade dos animais, não houve diferença para ganho de peso diário $(\mathrm{P}>0,05)$, consumo de ração diário $(\mathrm{P}>0,05)$ e conversão alimentar $(\mathrm{P}>0,05)$. Não houve diferença para consistência fecal $(\mathrm{P}>0,05)$. O número de leucócitos aumentou aos 32 dias de idade, quando as dietas contendo prebióticos e probióticos foram utilizadas $(\mathrm{P}>0,05)$. A ração contendo prebiótico aumentou o número de monócitos $(\mathrm{P}<0,05) \mathrm{e}$ a dieta contendo antibiótico proporcionou maior número de basófilos $(\mathrm{P}<0,05)$, aos 36 dias de idade dos animais; o número de linfócitos não foi alterado pelas dietas experimentais $(\mathrm{P}>0,05)$. As dietas não promoveram alterações nas imunoglobulinas $\operatorname{IgA}$, $\operatorname{IgM}$ e $\operatorname{IgG}(\mathrm{P}>0,05)$. Conclui-se que o uso de prebióticos, probióticos e antibióticos não influenciou o desempenho dos animais dos 22 aos 54 dias de idade.

Palavras-chave: aditivos; consistência fecal; imunoglobulinas; suínos.

\begin{abstract}
The objective of this study was to evaluate the addition of the prebiotic mannan oligosaccharide (MOS 0.2\%), probiotic (Bacillus subtilis 30g/ton) and antibiotic (Bacitracin zinc $125 \mathrm{~g} /$ ton) to piglets' feed in the post-weaning phase. Eighty (Danbread x Agroceres) pigs were used, that is, 40 males and 40 females, with initial weight of $7.1 \pm 0.0175 \mathrm{~kg}$. A randomized block design was used with four treatments and five replicates: 1 - Control; 2 - Prebiotic; 3 - Probiotic; 4 - Antibiotic. The variables evaluated were average daily gain (ADG), daily feed intake (DFI), feed conversion (FC) fecal consistency and leukocyte count. At 43 days of age, the animals presented the same weight gain
\end{abstract}


$(\mathrm{P}>0.05)$; however, there was increased intake of the diet containing prebiotic $(\mathrm{P}>0.05)$, and feed conversion was better for control diet $(\mathrm{P}<005)$. In the period of 54 days of age of the animals, there were no differences in daily weight gain $(\mathrm{P}>0.05)$, daily feed intake $(\mathrm{P}>0.05)$ and feed conversion $(\mathrm{P}>0.05)$, and also no differences in fecal consistency $(\mathrm{P}>0.05)$. The number of leukocytes increased at 32 days of age when the diets containing prebiotics and probiotics were used $(\mathrm{P}>0.05)$. The diet containing prebiotics increased the number of monocytes $(\mathrm{P}<0.05)$, and the diet containing antibiotic provided greater number of basophiles $(\mathrm{P}<0.05)$ at 36 days of age. The number of lymphocytes was not altered by the experimental diets $(\mathrm{P}>0.05)$, the diets promoted no changes in the immunoglobulins $\operatorname{IgA}, \operatorname{IgM}$ and $\operatorname{IgG}(\mathrm{P}>0.05)$. The use of prebiotics, probiotics and antibiotics did not influence the animals' performance from 22 to 54 days of age.

Keywords: additives; fecal consistency; immunoglobulins; pigs.

Enviado em: 06 julho 2011

Aceito em: 16 outubro 2015

\section{Introdução}

É crescente a preocupação da comunidade científica mundial com a segurança alimentar, especialmente no que se refere ao uso de medicamentos antibióticos em rações para animais. A possibilidade do

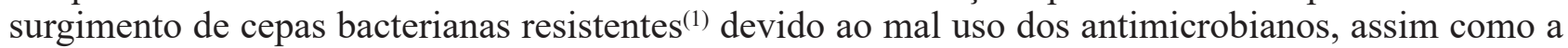
ocorrência de resíduos de medicamentos na carne suína ${ }^{(2)}$ têm motivado a pesquisa por aditivos de rações que possibilitem a manutenção da saúde dos animais sem que o desempenho zootécnico ou a salubridade do alimento sejam comprometidos. Neste contexto, o uso de probióticos e prebióticos como alimentos funcionais, entre outros aditivos, tem sido uma alternativa bastante utilizada, visando à produção de alimentos mais saudáveis e isentos de resíduos de antibióticos ${ }^{(3)}$.

O conceito de alimentos funcionais passou a concentrar-se de maneira intensiva nos aditivos alimentares que podem exercer efeito benéfico sobre a composição da microbiota intestinal, além dos benefícios nutricionais ${ }^{(4)}$. Os probióticos podem ser definidos como sendo microrganismos vivos não patogênicos que afetam positivamente hospedeiros humanos ou animais ${ }^{(5,6)}$ e seus possíveis mecanismos de ação no controle da microbiota intestinal incluem a produção de substâncias antimicrobianas, exclusão competitiva de patógenos por sítios de ligação na mucosa intestinal, competição por nutrientes e modulação do sistema imune ${ }^{(7)}$. Os prebióticos, por sua vez, são definidos como carboidratos fermentáveis capazes de alterar a composição e atividade da microbiota gastrointestinal, conferindo benefícios à saúde do hospedeiro ${ }^{(8)}$, tendo seus efeitos atribuídos à função de substrato, estimulando o crescimento e estabilização das populações microbianas benéficas, em detrimento às demais ${ }^{(9)}$.

Uma série de artigos de investigações científicas em que os antibióticos promotores de crescimento foram substituídos por compostos probióticos e/ou prebióticos, no período correspondente à desmama dos suínos, foram produzidos ${ }^{(10-15)}$. Este período é considerado crítico na vida dos leitões e são inúmeros os fatores que contribuem para o estresse pós-desmame, os quais, comumente, resultam em diarreia e queda no desempenho ${ }^{(16)}$. Isto pode estar relacionado à queda na imunidade dos leitões e susceptibilidade à ação de microrganismo patogênicos, caracterizando o ambiente pós-desmame como de desafio sanitário elevado ${ }^{(17,18)}$.

Há uma tendência para o banimento do uso de antibióticos em rações e a manipulação da dieta dos leitões no período que sucede a desmama pode ser uma ferramenta funcional e benéfica para a sua saúde ${ }^{(19,20)}$. Considerando tais fatores, o presente trabalho foi conduzido com o objetivo de avaliar o desempenho, a consistência fecal e os parâmetros sanguíneos de suínos na fase de creche, suplementados com prebiótico, probiótico e antibiótico.

\section{Material e Métodos}

Os procedimentos envolvendo animais foram aprovados pelo comitê de ética da Universidade Federal 
de Lavras, Protocolo n ${ }^{\circ}$ 018/2010.

O experimento foi conduzido em galpão de creche, em 20 baias suspensas $(2,0 \times 1,5 \mathrm{~m})$. Utilizaram-se 80 leitões (Danbred X Agroceres), selecionados de um total de 2.000 animais, oriundos de uma granja comercial da região Sul de Minas Gerais. Foram utilizados 40 machos e 40 fêmeas, desmamados aos 22 dias de idade, com peso inicial de 7,1 $\pm 0,017 \mathrm{~kg}$.

O delineamento utilizado foi blocos ao acaso, sendo quatro tratamentos e cinco repetições. Os animais foram pesados individualmente e distribuídos nos blocos em função do peso. As dietas experimentais (Tabela 1) foram formuladas de forma a atender as exigências mínimas nutricionais dos leitões, durante o período de creche, ou seja, dos 22 aos 60 dias de idade, segundo o NRC ${ }^{(21)}$. Os tratamentos foram: 1 - dieta basal, 2 - dieta basal + prebiótico 0,2\% (mananooligossacarídeo), 3 - dieta basal + probiótico (Bacillus subtilis 30g/tonelada) e 4 - dieta basal + antibiótico (bacitracina de zinco 125 $\mathrm{g} /$ tonelada). A composição, em microrganismos, do probiótico adicionado às dietas dos leitões e o número de unidades formadoras de colônias (UFC) por grama de produto (Calsporin $®$ ) foi de $1 \mathrm{x}$ $10^{10} \mathrm{UFC} / \mathrm{g}$.

Tabela 1: Composição das dietas basais de leitões na fase de creche, dos 22 aos 60 dias de idade

\begin{tabular}{|c|c|c|}
\hline \multirow[t]{2}{*}{ Ingrediente (\%) } & \multicolumn{2}{|c|}{ Dietas } \\
\hline & Pré-inicial & Inicial \\
\hline Mitho moido & 35,00 & 44,50 \\
\hline Farelo de soja & 20,00 & 29,00 \\
\hline Açúcar & 3,00 & 3,00 \\
\hline Óleo de soja & 2,00 & 1,50 \\
\hline Núcleo pré-inicial leitões ${ }^{1}$ & 40,00 & 20,00 \\
\hline Núcleo inicial ${ }^{2}$ & - & 2,00 \\
\hline Total & 100,00 & 100,00 \\
\hline \multicolumn{3}{|l|}{ Níveis nutricionais } \\
\hline $\mathrm{PB}(\%)$ & 20,00 & 21,13 \\
\hline $\mathrm{EM} \mathrm{kcal} / \mathrm{kg}$ & 3.560 & 3.428 \\
\hline Cálcio (\%) & 0,60 & 0,69 \\
\hline Fósforo disponivel (\%) & 0,50 & 0,46 \\
\hline Lisina digestivel & 1,282 & 1,226 \\
\hline Met + Cis digestivel & 0,779 & 0,711 \\
\hline Treonina digestivel & 0,850 & 0,804 \\
\hline Triptofano digestivel & 0,271 & 0,258 \\
\hline
\end{tabular}

Túcleo pré-inicial - Composição: soro de leite em pó desnatado, leite em pó integral, leite desnatado em pó, colina, soja extrusada, milho pré-gelatinizado, açúcar, ácido fumárico, óleo vegetal, fosfato bicálcico, treonina, triptofano, calcário calcítico, premix mineral, L-lisina, premix vitamínico, cloreto de sódio, DL-metionina, hidróxido de tolueno butilato (B.H.T.) - Niveis por $\mathrm{kg}$ de produto: Vitamina A (360.000UI), Vitamina D3 (7.500U.I), Vitamina E (450 mg), Vitamina K3 (18 mg), Tiamina (12 mg), Riboflavina (29,5 mg), Piridoxina (13,5 mg), Vitamina B12 (0,01 mg), Niacina (118 mg), Acido Pantotênico (47,5 mg), Acido fólico (3,25 mg), Biotina (0,75 mg), Vitamina C (300 mg), Colina (1.500 mg), B.H.T. (300 mg), Ferro ( $875 \mathrm{mg})$, Cobre $(625 \mathrm{mg})$, Manganês (180 mg), Zinco (625 mg), Cobalto (3,25 $\mathrm{mg})$, Selênio ( $1 \mathrm{mg})$.

${ }^{2}$ Núcleo inicial - Composição: ácido fólico, ácido pantotênico, biotina, calcário calcítico, caulin, cloreto de colina, cloreto de sódio, fosfato bicálcico, aditivo antioxidante (B.H.T.), iodato de cálcio, niacina, óxido de zinco, vitamina B6, vitamina $B 2$, selenito de sódio, sulfato de cobalto, sulfato de cobre, sulfato de manganês, sulfato de ferro, vitamina $B 1$, vitamina $A$, vitamina $B 12$, vitamina $\mathrm{C}$, vitamina D3, vitamina $\mathrm{E}$, vitamina $\mathrm{K} 3$. Niveis por $\mathrm{kg}$ do produto: Ácido fólico (39 mg), ácido pantotênico (625 mg), B.H.T. (1.500), biotina ( $8 \mathrm{mg})$, cálcio (145 mg), cobalto (10 mg), cobre (4.375 $\mathrm{mg})$, colina (9.000 mg), ferro (2.780 mg), fósforo (41 mg), iodo (45 mg), manganês (1.360 mg), niacina (1.250 mg), selênio (13 mg), sódio (4l g), vitamina A (380.000U.I), vitamina B1 (60 mg), vitamina $B 12(940 \mathrm{mcg})$, vitamina $B 2$ ( $310 \mathrm{mg}$ ), vitamina B6 ( $80 \mathrm{mg})$, vitamina C (1250 mg), vitamina D3 (60.000 U.I), vitamina E (1.250 mg), vitamina K3 (125 mg), zinco ( $3.750 \mathrm{mg})$. 
As variáveis de desempenho analisadas foram o ganho de peso diário (GPD), o consumo de ração diário (CRD) e a conversão alimentar (CA). O desempenho foi obtido após a pesagem dos animais, medindo-se o fornecimento e as sobras de ração. As sobras foram coletadas, secadas, pesadas e descontadas do total fornecido para a determinação do consumo real. A conversão alimentar foi obtida pela relação consumo/ganho de peso no período.

Após jejum de 8 horas, realizou-se a eutanásia de um animal por parcela, aos 29, 36 e 54 dias de idade, para coleta das amostras de sangue. Amostras de sangue contendo $10 \mathrm{~mL}$ foram coletadas em tubo de ensaio, uma contendo anticoagulante EDTA. As análises de leucócitos totais foram realizadas por meio de citometria de fluxo, estabelecendo-se as quantidades de leucócitos totais, eosinófilos, monócitos, basófilos e linfócitos por $\mathrm{mm}^{3}$ de sangue.

Para a análise da consistência fecal, as fezes foram classificadas diariamente nas baias, em uma escala de 0 a 3 , em que 0 e 1 foi adotado para fezes normais, 2 para pastosas e 3 para aquosas.

As análises estatísticas foram realizadas utilizando-se o PROC GLM do pacote estatístico SAS (Statistical Analysis System Institute - SAS INSTITUTE, 2001) ${ }^{(22)}$. Utilizou-se o teste de Lilliefors para a verificação da normalidade da distribuição dos dados que foram, posteriormente, submetidos à análise de variância global com todos os tratamentos, para obtenção do quadrado médio do resíduo. Para as variáveis de desempenho, aplicou-se o teste de Tukey, a 5\%. Para as variáveis sanguíneas (leucócitos totais) foi utilizada a opção de transformação raiz quadrada de $x+0,5$. A consistência fecal foi submetida à análise não paramétrica (qui quadrado), sendo as médias comparadas pelo teste Kruskal-Walis.

\section{Resultados e Discussão}

Não se observou efeito $(\mathrm{P}>0,05)$ da adição de probiótico, prebiótico ou antibiótico no GPD dos animais $(\mathrm{P}>0,05)$; no entanto, o maior $\mathrm{CRD}(\mathrm{P}<0,05)$ foi observado para os animais alimentados com rações contendo prebiótico e a menor $\mathrm{CA}(\mathrm{P}<0,05)$ foi verificada para os animais alimentados com a ração controle. Como relatou $\mathrm{Saad}^{(4)}$, a ingestão de ração com adição de prebióticos exerce efeito de aumento de volume da digesta como consequência do aumento da biomassa microbiana, que pode resultar em aumento da frequência de evacuações, confirmando sua ação semelhante à fibra dietética e subsidiando o resultado de aumento no CRD observado. Resultados semelhantes foram encontrados por Utiyama et al. ${ }^{(23)}$, que verificaram aumento do CRD dos animais em função da adição de prebiótico nas rações dos leitões.

O uso de Bacillus toyoi como probiótico em detrimento do uso de antimicrobiano foi testado por Fedalto et al. ${ }^{(24)}$, que não observaram efeito para o desempenho de leitões no período pós-desmama, o que está de acordo os resultados obtidos neste experimento. Resultados semelhantes para GPD e CA também foram obtidos por Santos et al. ${ }^{(25)}$, que utilizaram níveis de manose de $0 \%$ a $0,2 \%$.

A utilização de probióticos e prebióticos não afetou o desempenho de leitões no período pós-desmama, como verificado por Sanches et al. ${ }^{(26)}$, que utilizaram probiótico, prebiótico e simbiótico na dieta pósdesmama e verificaram que o grupo controle e o que estava recebendo antibiótico apresentaram o mesmo desempenho. Por sua vez, Mikkelsen et al. ${ }^{(27)}$ não observaram diferenças no desempenho de leitões desmamados ao compararem a utilização de dois prebióticos distintos na dieta.

Não foi observada diferença $(\mathrm{P}>0,05)$ no desempenho dos animais submetidos às dietas testadas no período de 22 a 54 dias de idade (Tabela 3 ). Os resultados encontrados na literatura em que ingredientes funcionais foram avaliados são coerentes com a observação do status sanitário do local experimental. Muitos autores não verificaram efeito dos ingredientes potencialmente melhoradores da saúde, como probióticos ${ }^{(28,29)}$, prebióticos ${ }^{(25)}$, glutamina e ácido glutâmico ${ }^{(30)}$, lactose ${ }^{(31)}$, quando comparados às dietas controle, o que pode estar relacionado à ausência de desafio sanitário. No entanto, outros autores que comprovaram que, com o desafio sanitário, induzido ou naturalmente proporcionado pelas instalações, houve efeito positivo da inclusão dos ingredientes funcionais na dieta, como Estiene et al. ${ }^{(32)}$, que trabalharam com probióticos.

A importância do desafio sanitário para leitões na fase de desmame também foi estudada por Cromwell et al. ${ }^{(18)}$, que demonstraram a importância do manejo sanitário das granjas para o desempenho e a 
saúde dos leitões. Além disso, o núcleo utilizado nas dietas basais continha fontes de lactose que, de acordo com Molino et al. ${ }^{(31)}$, promove melhoria da saúde intestinal pelo aumento da população microbiana benéfica, tais como Lactobacillus spp.

Um dos problemas atribuídos à desmama precoce dos suínos é a redução do consumo de ração principalmente na primeira semana pós-desmame, que resulta em atrofia das vilosidades intestinais e queda na capacidade de aproveitamento dos nutrientes da ração, como relatado por Molino e Balbino $^{(33)}$. Portanto, ainda que não tenha sido verificado efeito significativo da adição de prebiótico, probiótico ou antibiótico sobre o desempenho dos animais dos 22 aos 54 dias, o maior CRD observado $(P<0,05)$ nos animais dos 22 aos 43 dias de idade alimentados com ração contendo prebiótico pode ser visto como aspecto positivo da inclusão deste ingrediente, já que uma das dificuldades para este período é a manutenção do consumo de ração.

Tabela 2: Ganho de peso diário (GPD), consumo de ração diária (CRD) e conversão alimentar (CA) dos leitões dos 22 aos 43 dias de idade, alimentados com rações ${ }^{1}$ contendo prebiótico, probiótico e antibiótico

\begin{tabular}{llll}
\hline Dieta experimental & GPMD $(\mathrm{g} / \mathrm{d})$ & CRMD $(\mathrm{g} / \mathrm{d})$ & CA \\
\hline Controle & 307 & $406 \mathrm{~b}$ & $1,32 \mathrm{a}$ \\
Prebiótico & 322 & $512 \mathrm{a}$ & $1,59 \mathrm{~b}$ \\
Probiótico & 279 & $446 \mathrm{ab}$ & $1,59 \mathrm{~b}$ \\
Antibiótico & 316 & $467 \mathrm{ab}$ & $1,47 \mathrm{ab}$ \\
\hline CV $(\%)$ & 9,91 & 10,34 & 6,35 \\
\hline
\end{tabular}

${ }^{1}$ Médias seguidas de letras diferentes na coluna diferem pelo teste de Tukey $(\mathrm{P}<0,05)$.

Tabela 3: Desempenho de leitões dos 22 aos 54 dias de idade, recebendo prebiótico, probiótico e antibiótico

\begin{tabular}{lccc}
\hline Tratamento & GPMD (g/d)* & CRMD (g/d)* & CA $^{*}$ \\
\hline Controle & 370 & 616 & 1,66 \\
Prebiótico & 418 & 656 & 1,57 \\
Probiótico & 388 & 578 & 1,49 \\
Antibiótico & 415 & 616 & 1,48 \\
\hline CV (\%) & 11,53 & 7,24 & 10,58 \\
\hline
\end{tabular}

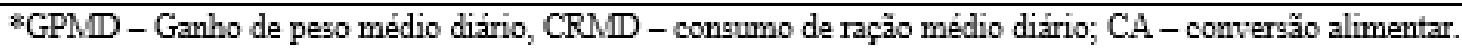

Não se observou efeito significativo na avaliação da consistência fecal (Tabela 4) para as dietas testadas nos animais. As condições sanitárias das instalações e dos animais podem ter sido determinantes para a não apresentação de um quadro de diarreia, não permitindo, assim, observar ação dos aditivos utilizados. A não observação de efeito das dietas sobre a consistência fecal dos leitões (Tabela 4) pode dar sustentação à suposição de que não houve desafio sanitário suficiente para comprometer a saúde dos leitões. Estes resultados estão de acordo com os resultados observados por Morais et al. ${ }^{(29)}$, que utilizaram probióticos combinados com Bacillus subtilis na dieta de leitões na fase de creche e não encontraram efeitos para desempenho e diarreia.

Por outro lado, Taras et al. ${ }^{(34)}$ afirmaram que os probióticos usados em dietas para suínos e aves têm efeito positivo na consistência das fezes e que os efeitos positivos no uso de probióticos são mais bem evidenciados quando os animais apresentam diarreia. $\mathrm{O} \mathrm{NRC}^{(21)}$ sugere que a espécie de microrganismo utilizada como probiótico, os históricos de doenças, a condição sanitária e a temperatura das instalações podem interferir na ação dos promotores de crescimento. 
Tabela 4: Consistência fecal $\%$ de leitões na fase de creche, no periodo de 22 a 54 dias de idade

\begin{tabular}{lcccc}
\hline \multirow{2}{*}{ Tratamento } & \multicolumn{4}{c}{ Escore(\%) } \\
\cline { 2 - 5 } & 0 & 1 & 2 & 3 \\
\hline Controle & 93,0 & 6,0 & 1,0 & 0,0 \\
Prebiótico & 84,0 & 12,0 & 3,0 & 1,0 \\
Probiótico & 85,0 & 11,0 & 3,0 & 1,0 \\
Antibiótico & 82,0 & 12,0 & 5,0 & 1,0 \\
\hline $\mathrm{P}=$ & 0,2928 & 0,4813 & 0,4662 & 0,9074 \\
\hline
\end{tabular}

Năo significativo pelo teate de Kruakal-Wallis $(P<0,05)$.

Os valores encontrados para leucócitos totais apresentaram-se dentro da normalidade para a espécie e a idade, de acordo com os dados apresentados por Eze et al. ${ }^{(35)}$. Observou-se maior resposta $(\mathrm{P}<0,05)$ para leucócitos, nos tratamentos que receberam prebióticos e probióticos, seguidos dos tratamentos contendo antibiótico e controle, aos 54 dias de idade dos animais.

As principais células de defesa do organismo são representadas pelos leucócitos, incluindo linfócitos, monócitos, neutrófilos e eosinófilos, e são fortemente influenciadas pela nutrição, estresse ou desordens clínicas ${ }^{(15)}$. Robles-Huaynate et al. ${ }^{(15)}$ relataram aumento na contagem de leucócitos em função da desmama dos leitões e sua diminuição em função da adição de probióticos nas rações.

$\mathrm{O}$ efeito imunoestimulante em animais pode estar relacionado à capacidade de os microrganismos com características probióticas interagirem com as placas de Peyer e as células epiteliais intestinais, estimulando as células B produtoras de $\operatorname{IgA}$ e a migração de células $\mathrm{T}$ do intestino ${ }^{(36)}$. Também tem sido demonstrado que os probióticos favorecem a atividade fagocítica inespecífica dos macrófagos alveolares, sugerindo uma ação sistêmica por secreção de mediadores que estimulariam o sistema imune $^{(37)}$. Chiquiere et al. ${ }^{(38)}$ obtiveram maior número de leucócitos na dieta controle em relação às demais rações contendo promotores de crescimento, justificando que há uma menor resposta do sistema imune quando não há tratamentos com promotores de crescimento.

A dieta contendo prebiótico apresentou maior estímulo para contagem de monócitos em comparação com as demais rações. Monócitos são células de resposta imune inata, portanto, já presentes antes de estímulos específicos $^{(39)}$. Verificou-se que, com o avançar da idade dos animais, naturalmente, eles apresentaram elevação nas concentrações (Tabela 5). Esse maior estímulo observado ao longo do período experimental pode estar relacionado à imunidade adaptativa e esses resultados podem ser devido à exposição natural a antígenos, ao ambiente ou até mesmo à alimentação e, possivelmente, não apresentam relação direta com o desempenho dos animais no período experimental de 32 dias.

Os animais submetidos à dieta contendo prebiótico apresentaram valores de contagem de eosinófilos mais elevados em relação aos animais das demais dietas (Tabela 5). Possivelmente, essa resposta é positiva para os animais aos 14 dias. Segundo Lima et al. ${ }^{(40)}$, os eosinófilos têm participação em reações alérgicas e na resposta aguda inflamatória, podendo induzir dano tecidual (eosinofilia). Estas células migram da circulação para os locais de infecção e inflamação, onde são importantes contra infecções por parasitas e/ou alergenos. $\mathrm{Kita}^{(41)}$ sugere que a regulação da produção e ativação dos eosinófilos ocorre por propriedades únicas e, talvez, não específicas destas células, como pela ação de enzimas proteolíticas produzidas por microrganismos e outras moléculas biológicas. Mesmo que os eosinófilos possam permanecer até duas semanas nos tecidos sob a influência das citocinas, permanecem apenas algumas horas no sangue ${ }^{(42)}$.

De acordo com os resultados encontrados para a contagem de basófilos, a dieta contendo prebiótico apresentou menor resposta em relação às demais rações. O tratamento positivo contendo antibiótico apresentou maior resposta para basófilos.

Não foram encontradas diferenças para contagem de linfócitos, para as dietas avaliadas nos períodos testados, provavelmente porque não houve desafio e não ocorreu estímulo para a resposta imune adaptativa.

Considerando-se somente os períodos, verificou-se que houve efeito $(\mathrm{P}<0,05)$ para os períodos 
avaliados com maior estímulo ao sistema imune. Esta maior ativação do sistema imune pode estar relacionada com o desenvolvimento da imunidade adaptativa dos animais.

Tabela 5: Leucócitos totais (células $/ \mathrm{mm}^{3}$ ) aos 7, 14 e 32 dias de experimento, de leitões recebendo prebiótico, probiótico e antibiótico

\begin{tabular}{|c|c|c|c|c|}
\hline \multirow{2}{*}{ Dietas } & \multicolumn{3}{|c|}{ Período (dias) } & \multirow[t]{2}{*}{ Média } \\
\hline & 7 & 14 & 32 & \\
\hline & \multicolumn{4}{|c|}{ Leucócitos } \\
\hline Controle & 17,1 & 20,2 & $16,3 \mathrm{~B}$ & 17,9 \\
\hline Prebiótico & $16,8 \mathrm{~b}$ & $18,8 \mathrm{~b}$ & $25,6 \mathrm{Aa}$ & 20,4 \\
\hline Probiótico & $13,8 \mathrm{~b}$ & $17,0 \mathrm{~b}$ & $27,6 \mathrm{Aa}$ & 19,5 \\
\hline Antibiótico & $12,6 \mathrm{~b}$ & $20,5 \mathrm{a}$ & $22,5 \mathrm{ABa}$ & 18,5 \\
\hline Média & 15,1 & 19,1 & 23,0 & \\
\hline$P=$ & 0,0001 & & & \\
\hline CV $(\%)$ & 12,36 & & & \\
\hline \multicolumn{5}{|c|}{ Monócitos } \\
\hline Controle & 0,90 & 1,92 & 3,02 & $1,95 \mathrm{BC}$ \\
\hline Prebiótico & 2,52 & 3,14 & 4,46 & $3,37 \mathrm{~A}$ \\
\hline Probiótico & 0,56 & 1,30 & 3,36 & $1,74 \mathrm{C}$ \\
\hline Antibiótico & 1,48 & 1.66 & 4.02 & $2.39 \mathrm{~B}$ \\
\hline Média & $1,37 \mathrm{~b}$ & $2,01 \mathrm{~b}$ & $3,72 \mathrm{a}$ & \\
\hline$P=$ & 0,0000 & & & \\
\hline CV (\%) & 22,34 & & & \\
\hline \multicolumn{5}{|c|}{ Eosinófilos } \\
\hline Controle & 0,42 & $0,64 \mathrm{~B}$ & 0,52 & 0,53 \\
\hline Prebiótico & $0,42 \mathrm{~b}$ & $1.28 \mathrm{Aa}$ & $0,32 \mathrm{~b}$ & 0,67 \\
\hline Probiótico & 0,32 & $0,44 \mathrm{~B}$ & 0,50 & 0,42 \\
\hline Antibiótico & 0,46 & $0,52 \mathrm{~B}$ & 0,70 & 0,56 \\
\hline Média & 0,41 & 0,72 & 0,51 & \\
\hline$P=$ & 0,0270 & & & \\
\hline $\mathrm{CV}(\%)$ & 15,31 & & & \\
\hline \multicolumn{5}{|c|}{ Basófilos } \\
\hline Controle & 0,96 & $0,34 \mathrm{AB}$ & 0,16 & 0,49 \\
\hline Prebiótico & 0,36 & $0,06 \mathrm{~B}$ & 0,20 & 0,21 \\
\hline Probiótico & 0,22 & $0,32 \mathrm{AB}$ & 0,38 & 0,31 \\
\hline Antibiótico & 0,20 & $1,30 \mathrm{~A}$ & 0,72 & 0,74 \\
\hline Média & 0,44 & 0,51 & 0,37 & \\
\hline $\mathrm{P}=$ & 0,0306 & & & \\
\hline CV (\%) & 27,77 & & & \\
\hline \multicolumn{5}{|c|}{ Linfócitos } \\
\hline Controle & 64,8 & 59,6 & 78,9 & 67,8 \\
\hline Prebiótico & 69,8 & 63,2 & 74,3 & 69,1 \\
\hline Probiótico & 64,2 & 63,3 & 75,6 & 67,7 \\
\hline Antibiótico & 66,5 & 61,6 & 77.3 & 68,5 \\
\hline Média & $66,3 \mathrm{~b}$ & $61,9 \mathrm{~b}$ & $76,5 \mathrm{a}$ & \\
\hline$P=$ & 0,0002 & & & \\
\hline CV (\%) & 3.46 & & & \\
\hline
\end{tabular}

\section{Conclusões}

Não houve efeito dos aditivos testados para suínos na fase pós-desmama, provavelmente em virtude da ausência de desafio sanitário. 


\section{Agradecimentos}

Os autores agradecem à FAPEMIG, Capes e CNPq pelo auxílio financeiro e aos Programas de Pósgraduação em Zootecnia e Ciências Veterinárias da Universidade Federal de Lavras pelo apoio às pesquisas.

\section{Referências}

1 Lopes GV. Caracterização de determinantes de resistência a antimicrobianos em isolados de salmonela entérica proveniente da cadeia produtiva da carne suína no sul do Brasil. Universidade Federal do Rio Grande do Sul, Porto Alegre, RS. Tese de Doutorado, Porto Alegre, RS, 2014. Disponível em http://hdl.handle. net/10183/95139.

2 Prestes OD, Martins ML, Friggi CA, Munaretto JS, Adaime MB, Zanella R. O estado da arte na determinação de resíduos de medicamentos veterinários em alimentos de origem animal empregando técnicas cromatográficas acopladas à espectrometria de massas. Química Nova. 2013;36(5):697-710. http://dx.doi.org/10.1590/S0100$\underline{40422013000500015}$

3 Silva LP, Nörnberg JL. Prebióticos na nutrição de não-ruminantes. Ciência Rural. 2003;33(5):983-990. http:// dx.doi.org/10.1590/S0103-84782003000500029

4 Saad SMI. Prebióticos e probióticos: o estado da arte. Revista Brasileira de Ciências Farmacêuticas. 2006;42(1):1-7. http://www.revistas.usp.br/rbcf/article/viewFile/44095/47716

5 Fuller R. Probiotics in man and animals. The Journal of Applied bacteriology. 1989;66(5):365-78. http:// dx.doi.org/10.1111/j.1365-2672.1989.tb05105.x

6 Sanders ME. Probiotics: definition, sources, selection, and uses clinical infection diseases. 2008;46 Suppl 2: S58-61. http://dx.doi.org/10.1086/523341

7 Bermudez-Brito M, Plaza-Díaz J, Muñoz-Quezada S, Gómez-Llorente C, Gil A. Probiotic mechanisms of action. Annual Nutrition and Metabolism. 2012;61(2):160-174. http://dx.doi.org/10.1159/000342079

8 Gibson GR, Probert HM, Loo JV, Rastall RA, Roberfroid MB. Dietary modulation of the human colonic microbiota: updating the concept of prebiotics. Nutrition Research Review. 2004;17(2):259-75. http://dx.doi. org/10.1079/NRR200479

9 Nogueira MG, Calveyra JC, Kich JD, Coldebella A, Mores N, Cardoso MRI. Efeito de probiótico na infecção e excreção fecal de Salmonella em suínos. Ciência Rural. 2012; 42(3):514-519. http://dx.doi.org/10.1590/ $\underline{\text { S0103-84782012000300021 }}$

10 Tucci FM, Thomaz MC, Pizauro Junior JM, Hannas MI, Scandolera AJ, Budiño FEL. Agentes tróficos na dieta de leitões desmamados sobre atividade de enzimas digestivas e o desempenho. Brazilian Journal of Veterinary Research and Animal Science. 2011;48(4):289-298. http://dx.doi.org/10.1590/S1413-95962011000400003

11 Silva SZ, Thomaz MC, Watanabe PH, Robles-Huaynate RA, Ruiz US, Pascoal LAF, Santos VM, Masson GCIH. Mananoligossacarídeo em dietas para leitões desmamados. Brazilian Journal of Veterinary Research Animal Science. 2012;49(2):102-110. http://dx.doi.org/10.11606/issn.2318-3659.v49i2p102-110

12 Afonso ER, Parazzi LJ, Marino CT, Martins SMMK, Silva CC, Gameiro AH, Moretti AS. Associação de probióticos adicionados à dieta de leitões no aleitamento e na creche, índices zootécnicos e economicidade. Revista Brasileira de Saúde e Produção Animal. 2013;14(1):161-176. http://revistas.ufba.br/index.php/rbspa/ article/view/2618/1391

13 Névoa ML, Caramori Junior JG, Correa GSS, Arantes VM, Kamimura R, Gonçalves FC, Oliveira MSF, Santos AL, Nalon RP. Desempenho e características bioquímicas de leitões submetidos à dietas com aditivos probióticos, prébióticos, simbióticos e antibióticos. Arquivo Brasileiro de Medicina Veterinária e Zootecnia. 2013;65(2):447-454. http://dx.doi.org/10.1590/S0102-09352013000200021 
14 Pietro ML, O'Sullivan L, Tan SP, McLoughlin P, Hughes H, O’Donovan O, Rea MC, Kent RM, Cassidy JP, Gardiner GE, Lawlo PG. Evaluation of the efficacy and safety of a marine-derived Bacillus Strain as an in-feed probiotic for Newly weaned piglets. PloS ONE. 2014; 9(2):1-12. http://dx.doi.org/10.1371/journal. pone. 0088599

15 Robles-Huaynate RA, Thomaz MC, Santana AE, Masson GCIH, Amorim AB, Silva SZ, Ruiz US, Watanabe PH, Budiño FEL. Efeito da adição de probiótico em dietas de leitões desmamados sobre as características do sistema digestório e do desempenho. Revista Brasileira de Saúde e Produção Animal. 2013;14(1):248-258. http://dx.doi.org/10.1590/S1519-99402013000100009

16 Kummer R, Gonçalves Mad, Lippke RT, Marques BMFPP, Mores TJ. Fatores que influenciam o desempenho dos leitões na fase de creche. Acta Scientiae Veterinariae. 2009;37 Suppl 1:S195-209. http://www.ufrgs.br/ actavet/37-suple-1/suinos-22.pdf

17 Castillo M, Martín-Orúe SM, Nofrarías M, Manzanilla EG, Gasa J. Changes in caecal microbiota and mucosal morphology of weaned pigs. Veterinary Microbiology. 2007;124(3-4):239-247. http://dx.doi. org/10.1016/j.vetmic.2007.04.026

18 Cromwell GL, Allee GL, Mahan DC. Assessment of lactose level in the mid- to late-nursery phase on performance of weanling pigs. Journal of Animal Science. 2008;86:127-133. http://dx.doi.org/10.2527/ jas.2006-831

19 Gaggìa F, Mattarelli P, Biavati B. Probiotics and prebiotics in animal feeding for safe food production. International Journal of Food Microbiology. 2010;141:15-28. http://dx.doi.org/10.1016/j. ijfoodmicro.2010.02.031

20 Rai V, Yadav B, Lakhani GP. Applications of probiotic and prebiotic in animals production: a review. Enviroment and Ecology. 2013;31(2B):873-876.

21 National Research Council. Nutrient requeriment of swine. Washington: National Academy, 1998. 189 p.

22 SAS Institute. Statistical Analysis System Institute. System for Microsoft Windows. Version 8.2. Cary, 2001.

23 Utiyama CA, Oetting LL, Giani PA, Ruiz US, Miada VS. Efeitos de antimicrobianos, prebióticos, probióticos e extratos vegetais sobre a microbiota intestinal, a freqüência de diarréia e o desempenho de leitões recém desmamados. Revista Brasileira de Zootecnia. 2006;35(6):2359-2367. http://dx.doi.org/10.1590/S1516$\underline{35982006000800023}$

24 Fedalto LM, Tkacz M, Ader LP. Probioticos na alimentação de leitões do desmame ao 63 dias de idade. Archives of Veterinary Science. 2002;7(1):83-88. http://dx.doi.org/10.5380/avs.v7i1.3973

25 Santos WG, Filgueiras EP, Bertechini AG; Fialho ET, Lima JAF, Brito MAVP. Manose na alimentação de leitões na fase de creche: desempenho, $\mathrm{pH}$ do tratogastrintestinal e peso de órgãos. Ciência e Agrotecnologia. 2003;27(3):696-702. http://dx.doi.org/10.1590/S1413-70542003000300027

26 Sanches AL, Lima JAF, Fialho ET, Murgas LDS, Almeida EC, Vieira Neto J, Freitas RTF. Utilização de probiótico, prebiótico e simbiótico em rações de leitões ao desmame. Ciência e Agrotecnologia. 2006;30(4):774777. http://dx.doi.org/10.1590/S1413-70542006000400026

27 Mikkelsen LL, Jakobsen M, Jensen BB. Effects of dietary oligosaccharides on microbial diversity and fructooligosaccharide degrading bacteria in faeces of pigs post-weaning. Animal Feed Science and Technology. 2003;109(6):144-150. http://dx.doi.org/10.1016/S0377-8401(03)00172-X

28 Taras D, Vahjen MM, Simon O. Performance, diarrhea incidence, and occurrence of Escherichia coli virulence genes during long-term adminstration of a probiotic Enterococcus faecium strain to sows and piglets. Journal of Animal Science. 2006;84(3):608-617. http://dx.doi.org/2006.843608x

29 Morais KMCMT, Berto DA, Hauptli L, Wechsler FS, Trindade Neto MA. Probióticos para leitões lactentes na fase de creche. Veterinária e Zootecnia. 2010;17(4):519-527. http://www.fmvz.unesp.br/rvz/index.php/rvz/ article/view/55

30 Molino JP, Donzele JL, Oliveira RFM, Saraiva A, Haese D, Fortes EI, Souza MF. L-glutamine and 
L-glutamate in diets with different lactose levels for piglets weaned at $2 \backslash 1$ days of age. Revista Brasileira de Zootecnia. 2012;41(1):98-105. http://dx.doi.org/10.1590/S1516-35982012000100015

31 Molino JP, Donzele JL, Oliveira RFM, Ferreira AS, Moraes CA, Haese D, Saraiva A, Oliveira JP. Lactose levels in diets for piglets weaned at 21 days of age. Revista Brasileira de Zootecnia. 2011;40(6):1233-1241. http://dx.doi.org/10.1590/S1516-35982011000600011

32 Estienne MJ, Hartsock TG, Harper AF. Effects of antibiotics and probiotics on suckling pig and weaned pig performance. Journal of Applied Research in Veterinary Medicine. 2005;3(4):303-308. http://www.jarvm.com/ articles/Vol3Iss4/ESTIENNE\%20IJARVM\%20V3N4.pdf

33 Molino JP, Balbino EM. Lactose em rações para leitões desmamados. Revista Eletrônica Nutritime. 2010;7(1):1133-1149. artigos/103V7N1P1133 1149JAN2010_.pdf

http://www.nutritime.com.br/arquivos internos/

34 Taras D, Vahjen MM, Simon O. Probiotics in pigs: modulation of their intestinal distribution and of their impact on health and performance. Livestock Science. 2007;108(1/3):229-231. http://dx.doi.org/10.1016/j. livsci.2007.01.075

35 Eze JI, Onunkwo JI, Shoyinka SVO, Chah FK, Ngene AA, Okolinta N, Nwanta JA, Onyenwe IW. Haematological profiles of pigs raised under intensive management system in South-eastern Nigeria. Nigerian Veterinary Journal. 2010;31(2):115-123. http://www.ajol.info/index.php/nvj/article/view/68958/57017

36 Perdigón G, Holgado APR. Mechanisms involved in the immunostimulation by lactic acid bacteria. In: Fuller R, Perdigón G. Probiotics 3: Immunodulation by gut microflora and probiotics. Dordrecht: Kluwer academic, 2000, p. 213-233.

37 Cross M L. Microbes versus microbes: immune signals generated by probiotic lactobacilli and their role in protection against microbial pathogens. FEMS Immunology and Medical Microbiology. 2002;34(4):245-253. http://dx.doi.org/10.1111/j.1574-695X.2002.tb00632.x

38 Chiquieri J, Soares RTRN, Hurtado Nery VL, Carvalho ECQ, Costa APD. Bioquímica sangüínea e altura das vilosidades intestinais de suínos alimentados com adição de probiótico, prebiótico e antibiótico. Revista Brasileira de Saúde e Produção Animal. 2007;8(2):97-104. http://revistas.ufba.br/index.php/rbspa/article/ view/739/479

39 Geissmann F, Manz MG, Jung S, Sieweke MH, Merad M, Ley K. Development of monocytes, macrophages and dendritic cells. Science. 2010;327(5966):656-661. http://dx.doi.org/10.1126/science.1178331

40 Lima LR, Cavalcante RRL, Martins MCC, Parente DM, Cavalcante AAMC. Avaliação da atividade antiedematogênica, antimicrobiana e mutagênica das sementes de Amburana cearensis (A. C. Smith) (Imburanade-cheiro). Revista Brasileira de Plantas Medicinais. 2013;15(3):415-422. http://dx.doi.org/10.1590/S1516$\underline{05722013000300015}$

41 Kita H. Eosinophils: multifunctional and distinctive properties. International Archives of Allergy and Immunology. 2013;161(Suppl 2):S3-9. http://dx.doi.org/10.1159/000350662

42 Lilliehöök I, Tvedten H. Investigation of hypereosinophilia and potential treatments. Veterinary Clinics of North America, Small Animal Practice. 2003;33(6):1359-1378._http://dx.doi.org/10.1016/S0195$\underline{5616(03) 00097-4}$ 